\title{
FURTHER OBSERVATIONS ON STRESS-GENERATED ICE IN THE BLUE GLACIER, WASHINGTON, U.S.A.
}

\author{
By Charles A. Knight \\ (National Center for Atmospheric Research, ${ }^{*}$ Boulder, Colorado 80302, U.S.A.) \\ and E. LaChapelle \\ (Department of Atmospheric Sciences, University of Washington, Seattle, Washington 98105, \\ U.S.A.)
}

\begin{abstract}
A more detailed examination is made of the stress-generated ice crystallization features already discussed by LaChapelle (1968), using mainly thin-section techniques. The crystallization features on the walls of a tunnel within the Blue Glacier are localized at fine-grained layers and are fed by liquid water traveling along grain boundaries within the wall and within the deposits themselves. The water filling the crevasse encountered at the end of the tunnel was freezing uniformly to the crevasse walls as well as forming Thomson crystals within the water, and the evidence points to an important role for constitutional supercooling in the Thomson crystal formation. The forms of most of the Thomson crystals are explainable qualitatively by heat flow effects.

RÉsumÉ. Autres observations sur la production de glace par contrainte dans le Blue Glacier. Un examen plus détaillé est fait des caractéristiques des figures de cristallisation de la glace formée par contrainte déjà discutée par LaChapelle ( 1968 ) utilisant principalement les techniques des lames minces. Les figures de cristallisation sur les murs d'un tunnel à l'intérieur du Blue Glacier se trouvent dans les couches à grains fins et sont alimentées par de l'eau liquide circulant le long des limites de grain à l'intérieur des dépôts eux mêmes. La crevasse remplie d'eau recontrée au bout du tunnel était uniformement fermée par le gel formant aussi bien des cristaux Thomson à l'intérieur de l'eau; l'évidence marque un rôle important à l'eau surfondue dans la formation de cristaux Thomson. Les formes de la plupart des cristaux Thomson sont explicables qualitativement par les effets d'écoulement de chaleur.
\end{abstract}

Zusammenfassung. Weitere Beobachtungen an spannungserzeugtem Eis im Blue Glacier. Eine detailliertere Untersuchung der Kristallisationserscheinungen an spannungserzeugtem Eis, wie sie schon LaChapelle (1968) diskutiert hat, wird vor allem unter Anwendung der Dünnschlifftechnik vorgenommen. Die Krista!lisationserscheinungen an den Wänden eines Tunnels im Blue Glacier treten in feinkörnigen Schichten auf. Sie werden von Wasser genährt, das entlang der Korngrenzen in der Wand und innerhalb der Ablagerungen selbst fliesst. Die am Tunnelende angetroffene wassergefüllte Spalte schloss sich beim Gefrieren sowohl gleichförmig als auch unter Bildung von Thomsenkristallen im Wasser, und der Augenschein deutet auf eine wichtige Rolle von immanenter Unterkühlung bei der Bildung der Thomsenkristalle. Die Formen der meisten Thomsenkristalle lassen sich qualitativ als Folgen des Wärmeflusses erklären.

\section{INTRODUCTION}

This paper describes and discusses some of the crystallographic features of the ice that formed on the walls of a man-made tunnel in a temperate glacier and within a water-filled crevasse encountered when the tunnel was being drilled. Both the general principles involved (dependence of equilibrium melting point on stress, hydrostatic and otherwise) and the general features of the ice growth have been discussed by LaChapelle (1968).

The tunnel was excavated into the accumulation zone of the Blue Glacier (Mt. Olympus, Washington). It was approximately horizontal, about two meters high and one meter across, and extended $43 \mathrm{~m}$ in from the sloping surface. The head of the tunnel was about $20 \mathrm{~m}$ below the snow surface, and here there was a water-filled crevasse, roughly lens-shaped, approximately $6 \mathrm{~m}$ high, $\mathrm{I} \mathrm{m}$ wide, and $6-8 \mathrm{~m}$ long. The tunnel was excavated in the summer of 1966 , and the water drained out of the crevasse to the level of the tunnel floor. The remaining water was siphoned out in the summer of 1968 . This paper reports field work in the summers of 1967 and 1968 , and laboratory study of the samples obtained.

The large crevasse was profusely lined with large, single ice crystals of unusual morphologies. The basic cause of this crystal growth has been identified as conduction of heat out of the cavity along temperature gradients established by local relief of stress in ice under hydrostatic

* The National Center for Atmospheric Research is sponsored by the National Science Foundation. 
pressure. This effect was predicted by Thomson (1849), and this general class of crystals has been termed "Thomson crystals".

We divide the observations into three categories: (I) tunnel wall features; (2) solid wall-ice from the water-filled crevasse; and (3) the "free-growing", Thomson crystals in the crevasse.

\section{Tunnel wall features}

Ice formations on the wall of the tunnel, as observed in 1967 and 1968 , included icicles growing from the ceiling and the walls (LaChapelle, I968, figs. 8, 6), occasionally with ice "stalagmites" beneath; irregular or cauliflower-shaped large excrescences on walls and ceiling, often in rows (LaChapelle, I968, fig. 7); and rows of small ice bumps, often, but not always, parallel to the obvious ice foliation. Some of these features, as shown in some of the figures referred to, were also found on the crevasse walls one and two years after draining.

The only noteworthy feature of the single-crystal icicles not mentioned by LaChapelle is their frequent deviation from the vertical (his fig. 8), and its explanation. As was noted, they commonly terminate in a basal plane, and the ones that form at an angle have their $c$-axes at an angle, as shown in Fig. I. Thus the angle from the vertical is simply an expression of the familiar anisotropy of ice growth from supercooled water. The water from which the icicles formed became supercooled on relief of pressure as it was expelled from the glacier ice, and the presence of ice stalagmites below implies further that the supercooling of the water was not entirely eliminated in the icicle formation.

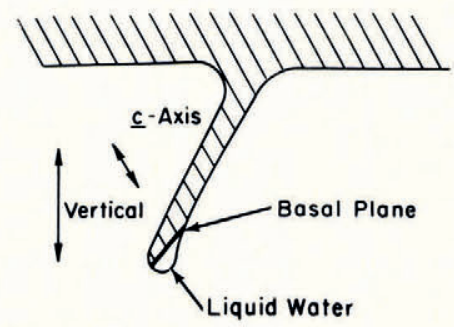

Fig. I. An icicle that forms at an angle to the vertical, in the process of growing. The angle is an expression of anisotropic growth rate, indicated by the basal plane.

Penetration of winter chill into the tunnel cannot be ruled out as a contributing factor to the freezing, but we feel that it was not a significant factor for the following reasons. The entrance to the tunnel was buried in snow in the early fall of both r 966 and 1967 . In the summer of 1967 there was no evidence of freezing of the surface of the water remaining in the crevasse at the head of the tunnel, though in 1968 there was some freezing of the surface. At the same time, icicles were more numerous and permanent in 1967 than in 1968 . There was no detectable air circulation in the tunnel, even with the entrance open. Most convincingly, icicles broken off during the summer of 1967 , when the outdoor air temperature was above freezing, formed noticeable new growth within one day.

The large excrescences and rows of small bumps are expressions of the same phenomenon that causes icicle formation. They are sometimes associated with icicle-like features, but usually not, in which case all of the water from the source must have frozen at the outlet. The question then arises, why does not the freezing of the water plug up the outlets? The answer is clear from the structure of the deposits (Figs. 2, 3), which exhibit coarse grains, regular, polyhedral grain shapes, and air bubbles along the triple grain boundaries. These open grainboundary junctions, and perhaps the grain boundaries themselves, are the water supply channels. Such open grain boundary junctions were also observed in situ in these ice deposits. 
Thus there is a strong presumption that they formed with the deposit and not later, by water drainage. The deposit shown in Figs. 2 and 3 was sampled in 1967 , and had formed within one year.

Since there was no trace of icicle formation from the ceiling deposit shown in Figs. 2 and 3, or from many others like it, virtually all of the freezing must have been by heat conduction:

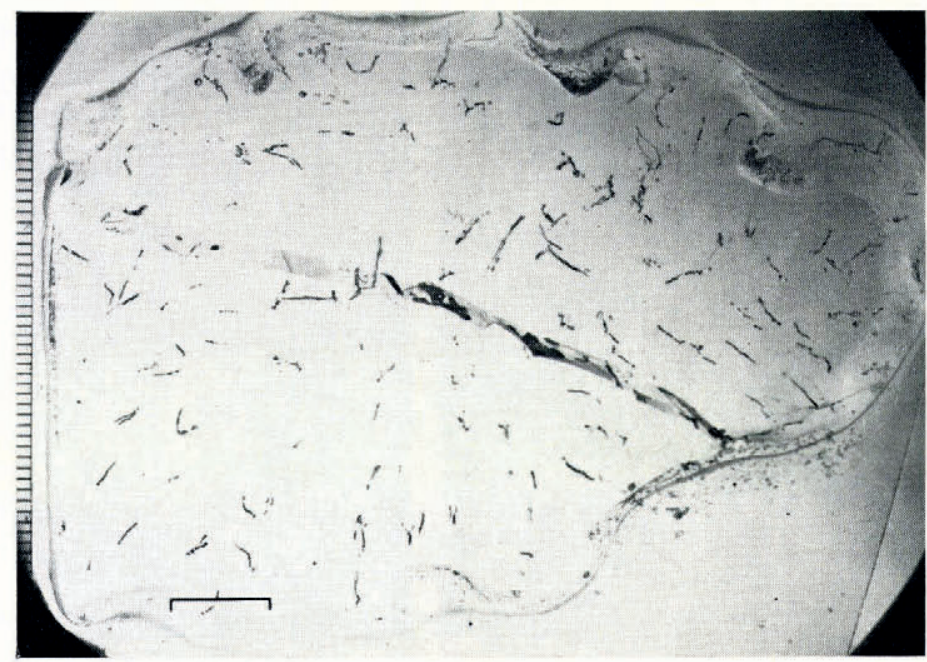

(a)

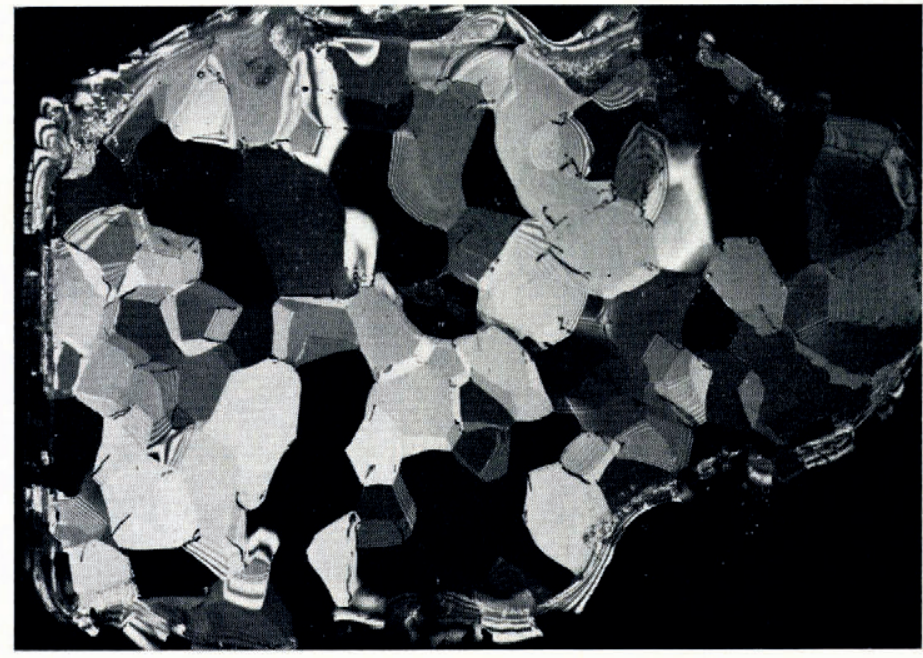

(b)

Fig. 2. Horizontal cross-section through part of an ice growth on the ceiling of the tunnel, scale in $(a)$ is $I \mathrm{~cm}$. (a) is with transmitted light, $(b)$ between crossed polaroids.

heat flowing from the deposit surface back through the deposit itself and into the colder glacier ice. Initial supercooling can provide only for freezing a minute portion of the liquid. However, the water flows through the deposit in the opposite direction from the heat flux. The reason that the grain boundaries stay open is probably to be found in interfacial free energy considerations (Steinemann, 1958). 
The second question to be answered with regard to these deposits is the cause of their localization. We selected the rows of small bumps (Fig. 4) for examination, and cut samples from the tunnel wall. Figure 5 shows sections cut parallel to the tunnel wall from a sample that included two closely-spaced, parallel rows of small bumps. Figure 6 shows a section from a similar sample of a sinuous line of bumps. Local layers of very fine-grained ice are the
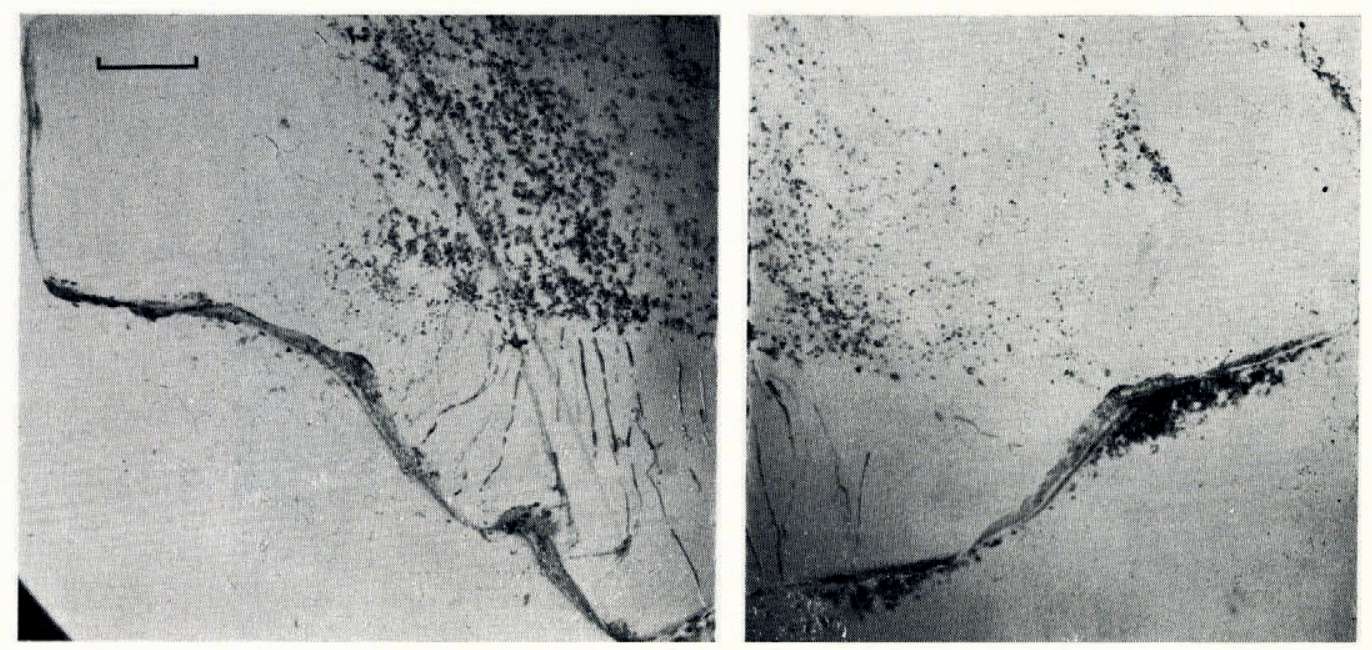

(a)
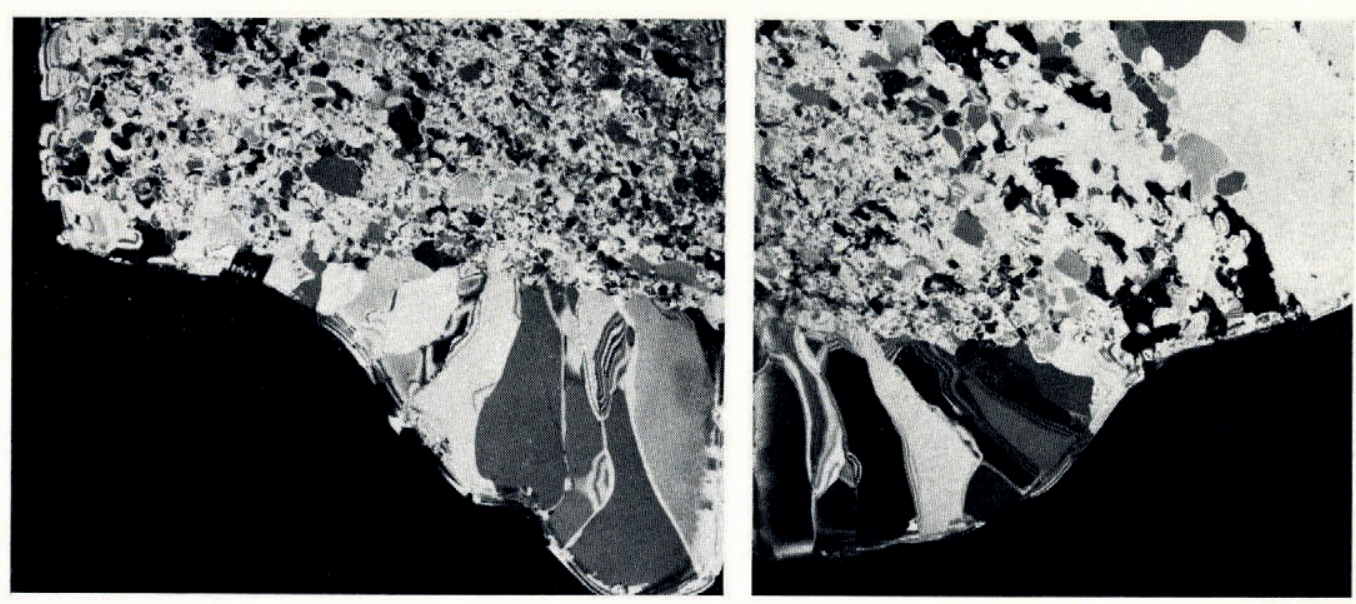

(b)

Fig. 3. Vertical cross-section through another part of the same ice growth shown in Fig. 2, including a portion of the tunnel ceiling. Scale in $(a)$ is I cm. Note the correlation of the growth with very fine-grained ice of the ceiling. (a) is with transmitted light, (b) between crossed polaroids.

sources of the water that forms the lines of bumps, just as the larger excrescences form at thicker, fine-grained layers (Fig. 3). The thinner layers are characteristically discontinuous, as shown in Figure $5 \mathrm{c}$. The fine-grained layers are also characterized by a distinctly different pattern of air bubbles (Figs. 3a, 5a), all of which are at grain boundaries, with a high preference for triple grain boundaries and their points of intersection. The lines of bumps and the excrescences sampled in 1967 were found again in 1968 , on the previously sawed faces. 
As was shown above, the grain boundaries are probably liquid, and this is the reason for the localization of the growth features at fine-grained portions of the tunnel walls. However, it is not clear from structural evidence whether the fine-grained layers are actual sources of liquid water formed by stress melting or merely conduits for liquid because of their small grain size. If these layers were associated with shear zones, as seems probable, stress melting would be a possible mechanism. But because the deposits themselves (Figs. 2 and 3 ) are not deformed, the layers can not be very active shear zones and may act merely as conduits. On the other hand, it would seem difficult for the small grain size to survive recrystallization, at the melting point, without some stress activity.

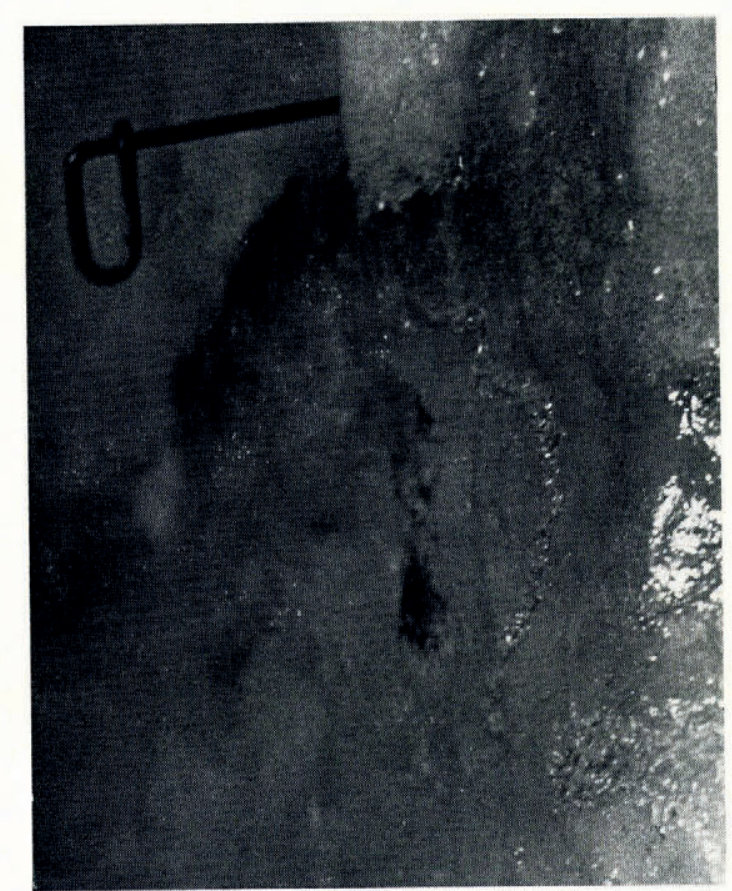

Fig. 4. A sinuous row of ice bumps below and to the right of the ice screw.

\section{WALL ICE FROM THE WATER-FILLED CREVASSE}

The water-filled crevasse was surrounded by a lining of bubble-free ice some $25^{-} 3^{0} \mathrm{~cm}$ thick. This zone unquestionably formed by the slow, inward freezing of the water because of the stress- and pressure-induced melting-point gradient (the Thomson effect). We studied its crystallographic structure from samples obtained in 1967 and examined surface features in place and from samples taken from the lower part of the crevasse in 1968 , immediately after syphoning out the water.

Figure 7 is a composite of thin sections showing the crystalline features of a slab of the bubble-free zone cut perpendicular to the wall surface. The wall surface encompassed by Fig. 7 is occupied by only two crystals, which have a very highly developed substructure, which is a convenient indicator of unrecrystallized wall growth. The rectangle defined by $\mathrm{A}-\mathrm{A}^{\prime}$ and $\mathrm{B}-\mathrm{B}^{\prime}$ is a single crystal. The many smaller crystals with much more uniform brightness (little or no substructure) are obviously the result of recrystallization. Irregular 
patches of substructured crystals, remnants of the original wall growth, can be found as far as I 7-I $8 \mathrm{~cm}$ from the wall surface. Patches separate from each other have orientation continuity. One such irregular group of remnants is in the area of the intersection between arrows $\mathrm{C}$ and $\mathrm{D}$ in Figure 7.

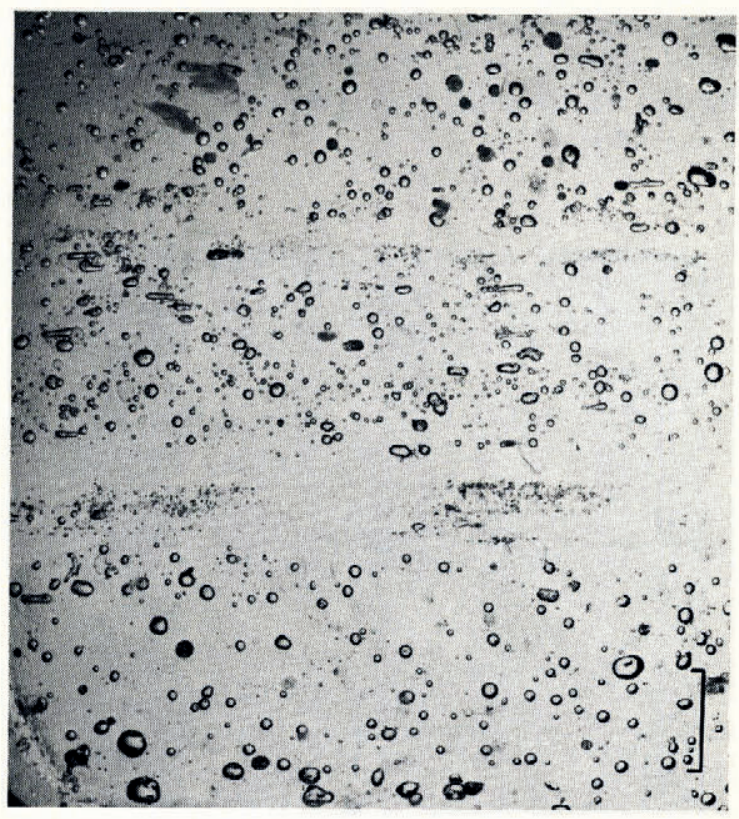

(a)

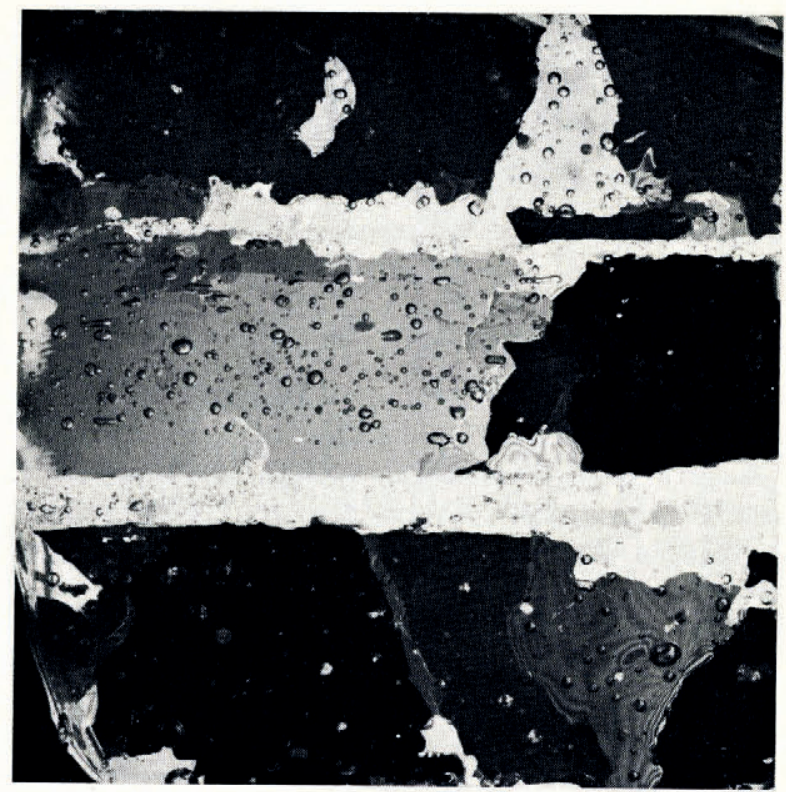

(b) 


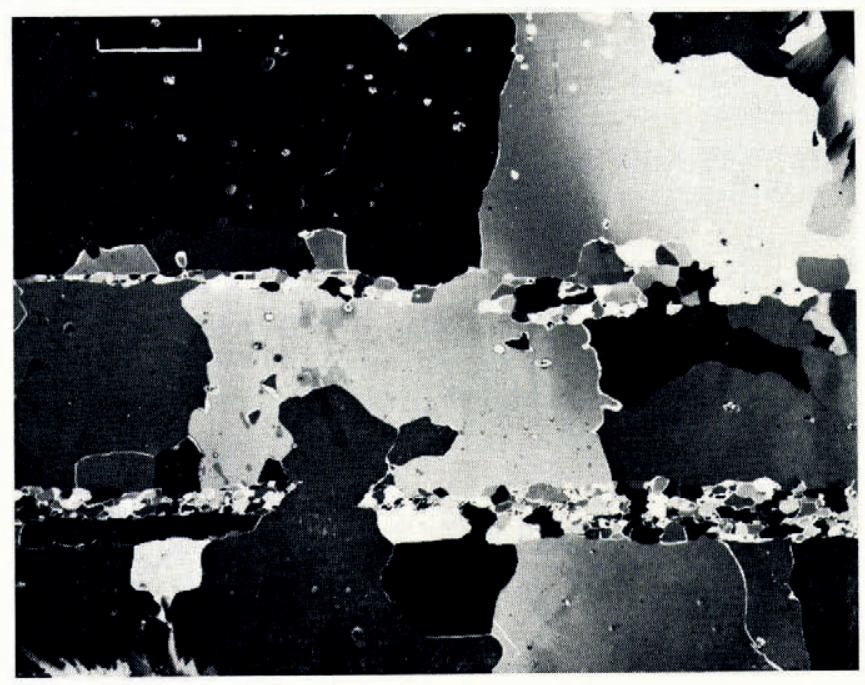

(c)

Fig. 5. Sections of the tunnel wall cut parallel to the wall surface just behind two parallel rows of ice bumps. Scales in (a) and $(c)$ are $1 \mathrm{~cm} .(a)$ and $(b)$ are thick sections seen in transmitted light and between crossed polaroids respectively. (c) is a thin section between crossed polaroids, in a different place from $(a)$ and $(b)$, showing more delailed crystal relationships.

Figure 7 does not include the contact between the clear and the bubbly ice. The contact was examined in thin section, and it showed neither crystalline discontinuity nor even a sharp bubble discontinuity. Crystal size was very large ( 2 to 5 crystals per $10 \mathrm{~cm} \times$ io $\mathrm{cm}$ section), and the crystals were regularly shaped in the portions examined, which appeared similar to Fig. 6 without the fine-grained layer.

The orientations of about twenty of the large crystals at the wall surface were measured and all were found to have their $c$-axes parallel to the wall surface. Some small crystals with other orientations were found, and could well have been cases where the recrystallization had caught up with the freezing, perhaps in the one year after drainage; it is very close in Fig. 7 . The extensive recrystallization obviated any attempt to find Thomson crystals that had been buried by the uniform wall growth.

A close examination of the wall icc in place revealed a large concentration of liquid inclusions, estimated to be at least $20 \%$ of the total volume of ice near the wall surface. The substructure was then critically examined, and was found to be due to the internal expansion that accompanies the freezing of trapped liquid inclusions: precisely the type always found in sea ice, that originates in the same way (Knight, 1962). It did not have the systematic arrangement of individual units or the uniformity of scale that characterizes the substructure in sea ice.

The water was drained from the lower part of the crevasse in 1968, in order to examine the morphology of the fresh ice-water interface. The faceting of the freshly exposed surface noted previously in I 966 was again observed (Fig. 8). The most striking form is groups of four-sided, similarly oriented, ice pyramids. The pyramids are formed by four $\left\{\boldsymbol{I O}_{\overline{\mathrm{I}}} \mathrm{I}\right\}$ planes. Groups of similarly oriented pyramids originate from a single crystal with an $a$-axis approximately perpendicular to the wall surface. Interfacial angles were not well enough preserved on collected specimens to make the identification from them, but they corresponded to the expected angles within $\pm 10^{\circ}$. The identification of the facets was made by etching, as is illustrated in Figure 9. 
After draining the water that had been standing in the crevasse to the level of the tunnel floor for two years, we found a $\mathrm{I}-2 \mathrm{~cm}$ step in the wall at the former water level, with the ice thicker below. This presumably represents approximately two years' growth, but we could not prove that the crevasse wall above the water had neither eroded nor grown during that period. The faceting of the originally drained part disappeared over the winter of $1966-67$ and was replaced by vertical, smooth grooves.

\section{THOMSON GRYSTALS}

The Thomson crystals, which grow individually into the water of the crevasse at a much faster rate than the rate of freezing of the wall ice, were described at some length by LaChapelle (1968). They present two main problems: first, the mechanism(s) by which the water in the crevasse, completely surrounded as it is by ice, becomes supercooled; and second, the cause of the wide variety of forms exhibited by the Thomson crystals.

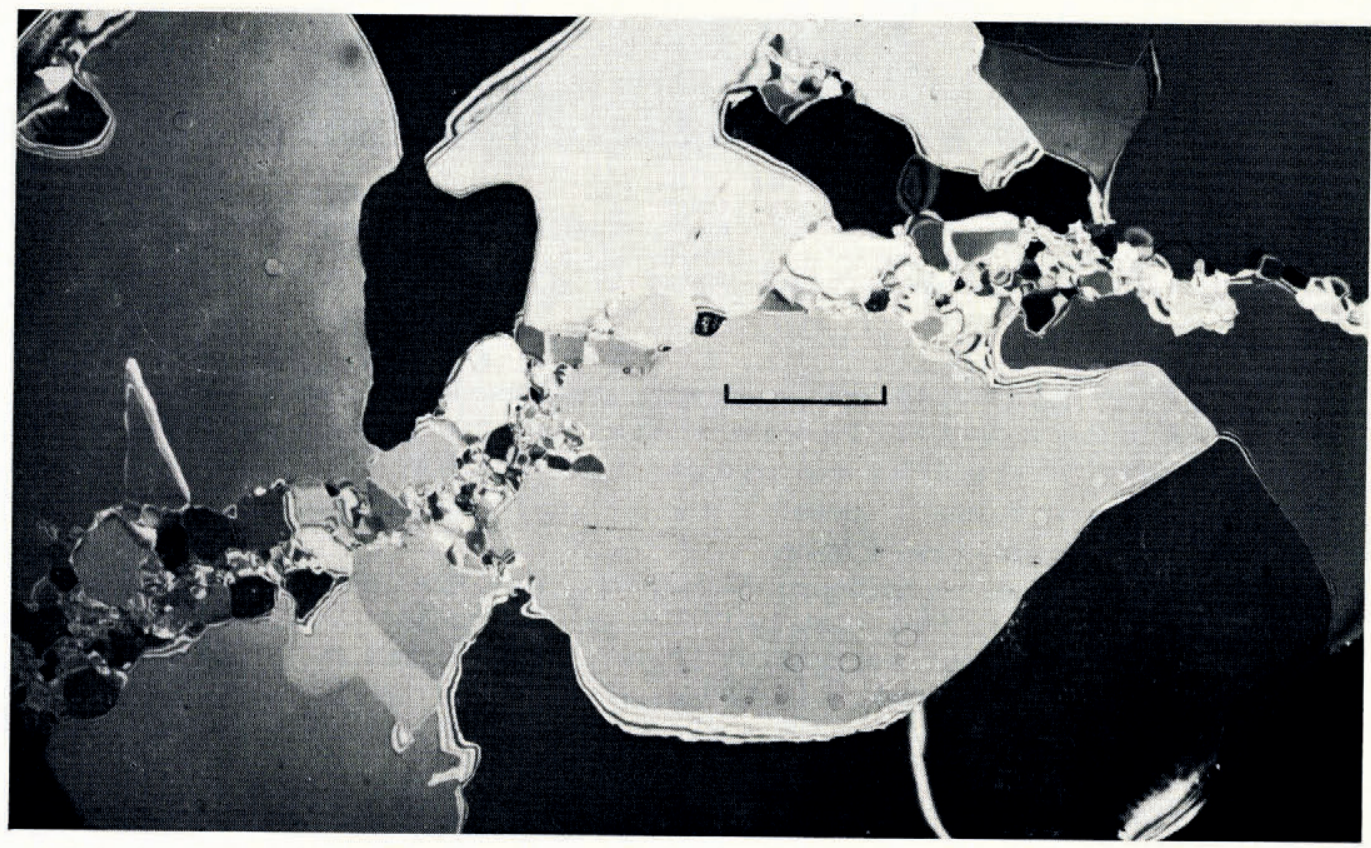

Fig. 6. Similar to Fig. $5(c)$ but section cut behind a single, sinuous line of ice bumps. Scale is $1 \mathrm{~cm}$.

The supercooling. Because the melting point of ice becomes lower with increasing pressure, the water within the crevasse must have a slight vertical temperature gradient: cooler at the bottom and warmer at the top. Any heat or material transport process within the water might be expected to deliver supercooled water to some places and to retard freezing or cause melting in others. The first possible process contributing to the supercooling of the bulk of the water is thus thermal convection within the water. The other three are direct seepage of supercooled water into the crevasse, non-hydrostatic stress at the wall surfaces themselves, causing the bulk of the water to be supercooled with respect to the unstressed Thomson crystals, and impurity effects.

The water in the crevasse, being colder at the bottom and warmer at the top, might be convectively unstable. In spite of a density gradient arising from this temperature gradient that would be unstable, the Joule-Thomson coefficient of water in the temperature range is 

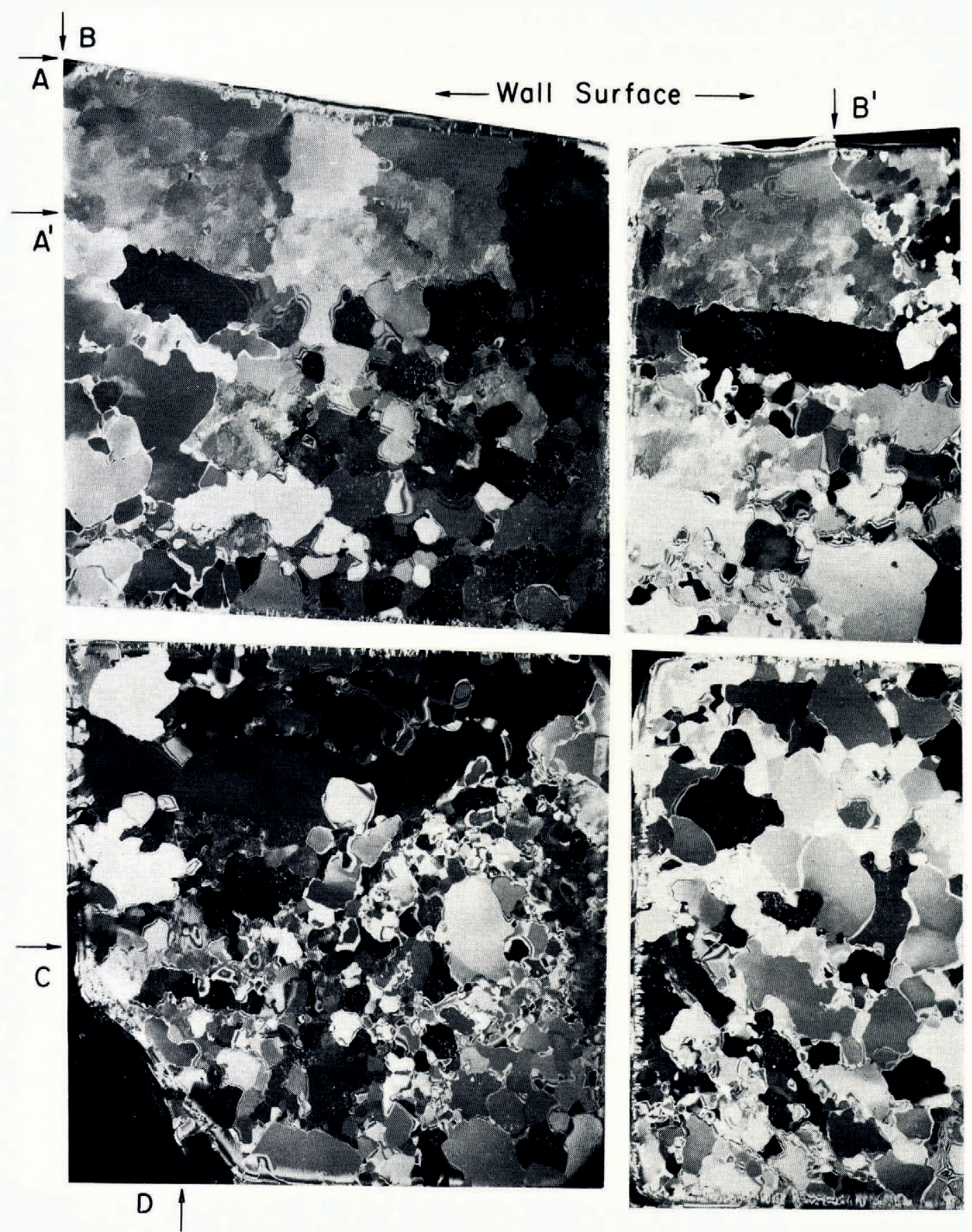

Fig. 7. Composite showing a large slice of the bubble-free, crevasse wall ice zone, cut perpendicular to the wall surface. Note the primary growth of very large crystals with extensive substructure, and the extensive recrystallization. Scale is $I \mathrm{~cm}$. 


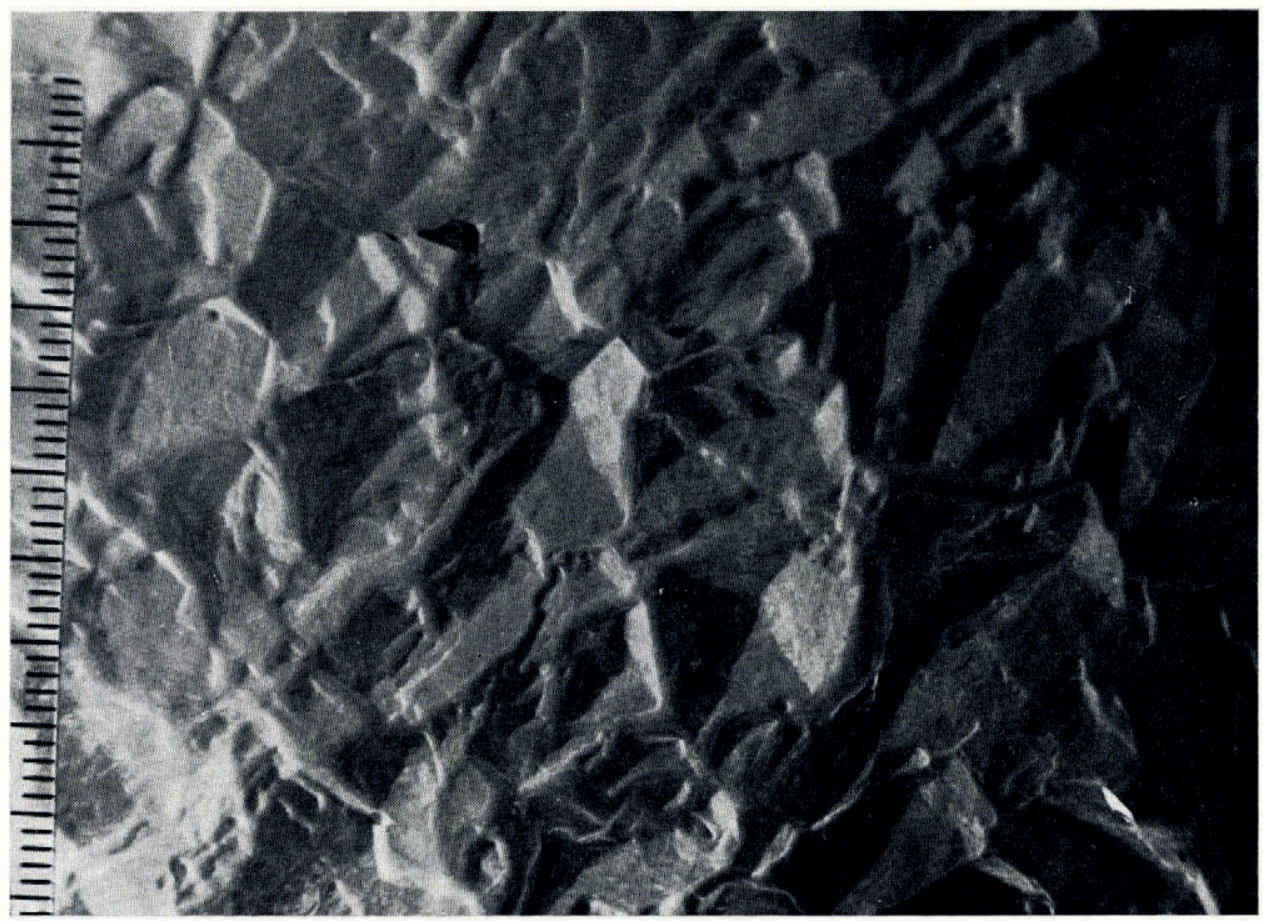

Fig. 8. Close-up of the crevasse wall surface just after drainage of the water, showing prominent faceting and pyramidal ice forms. Scale is in millimeters.

negative and of sufficient magnitude to overcome the instability. Thus the "potential density" gradient is stable. However, local convective adjustments may well occur in conjanction with other supercooling mechanisms, and the concentration of Thomson crystals near the top of the crevasse (LaChapelle, I968) probably arises from such convective adjustments.

Seepage of supercooled water from the walls of the tunnel has been demonstrated, and is to be expected to occur also at the walls of the water-filled crevasse, though at a slower rate because of the smaller pressure difference and larger grain size. This probably contributes to Thomson crystal formation, especially by determining where they grow by providing protuberences. But this is far from a sufficient source of supercooling. The volume of seepage would have to be thousands of times the volume of the crystals formed.

LaChapelle appealed to non-hydrostatic stress at the cavity walls themselves, as a means of supercooling the water with respect to unstressed crystals. However, if this were a major factor one would expect to see some effects that were not present. The Thomson crystals should grow faster just adjacent to the walls, and in so doing would inhibit the uniform, inward

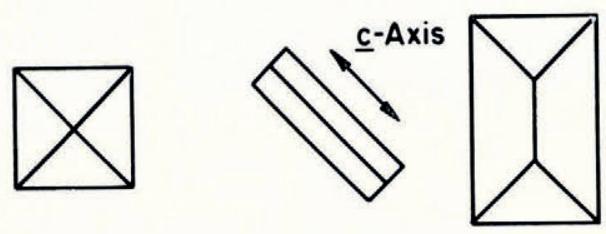

Fig. 9. Identification of the faceted pyramids (right and left) as being formed of four $\{10 \bar{I} I\}$ planes was by etching using the Formvar method. The etch pit shape corresponding to the pyramids shown is in the center. 
freezing of the walls and even cause melting. The Thomson crystals should thus be found sprouting from pockets in the walls, and should tend to spread laterally more than they extend outward. In fact, however, many of the Thomson crystals appeared to have grown more slowly near the walls, and no pocket formation was observed.

We therefore now feel that impurities (soluble organic and inorganic materials and dissolved air) may be responsible in large part for the supercooling. In the first place, a substantial amount of a grey, slimy material was found, both in the wall ice and, surprisingly, included within the Thomson crystals themselves. Furthermore, the presence of copious liquid inclusions within the wall ice (and within some of the Thomson crystals) shows the presence of impurities which lower the freezing point.

As the wall ice freezes slowly inward, the impurities in the water become concentrated near the wall because they can not be incorporated into the ice lattice. This lowers the freezing point of the water at the wall surface, and heat conduction then acts to supercool the water farther from the wall. (This familiar mechanism, important in sea-ice formation, is known as constitutional supercooling.) Thus, the supercooling in the water may increase as the impurity concentration decreases with distance away from the wall; in this case, assuming a steady state and if it were not for the Thomson crystals themselves and possible convection, the supercooling would be maximum at the center of the crevasse. The forms of the "mushroom" and arborescent crystals (LaChapelle, I968, figs. 4 and 2), and of many of the crystals observed in place in 1967 and 1968 , clearly showed slower growth near the wall and faster growth out into the water, proving increasing supercooling away from the wall and strongly indicating constitutional supercooling.

The development of $\left\{\operatorname{IO}_{\bar{I}} \mathrm{I}\right\}$ facets on the crevasse walls, which is to our knowledge the only observation of these faces forming in ice growth from water, is especially interesting in view of the fact that the Thomson crystals themselves generally do not develop $\left\{\operatorname{Io}_{\bar{I}} \mathrm{I}\right\}$ faces. There are two possible explanations for this. It may be an impurity adsorption effect (surface poisoning) that acts only in the impurity-enriched zone adjacent to the walls. Or, again, because of the impurity enrichment at the walls, the wall supercooling may be so low that "mock-lateral" growth (Jackson and others, I967) occurs on the $\left\{\mathrm{IO}_{\overline{\mathrm{I}} \mathrm{I}} \mathrm{\}}\right.$ planes simply because of the low supercooling. This would imply that the transition temperature between continuous and mock-lateral growth is higher for $\left\{\operatorname{IO}_{\bar{I}} \mathrm{I}\right\}$ than for $\left\{\mathrm{IO}_{\overline{\mathrm{I}} \mathrm{O}}\right\}$ planes, which would be very interesting and surprising. (We have failed to reproduce this morphology in the laboratory, using Helmholtz's method (1865), but have not yet used growth rates as slow as I cm per year.) According to either explanation, the presence of $\left\{\operatorname{Io}^{\overline{1}} \mathrm{I}\right\}$ facets on the walls but not on the Thomson crystals argues for an important effect of constitutional supercooling.

In summary, it seems likely that constitutional supercooling is the most important factor in the formation of the free-growing crystals in the water-filled crevasse. Wall stress and seepage contribute also, but probably in a very minor way. Both convection and heat conduction in the water may contribute to increasing supercooling in the upper part of the crevasse and lowering it in the lower part. In view of this interpretation, the name "Thomson crystal" for these crystals may not be entirely appropriate. However, since the Thomson mechanism (local stress relief in ice under pressure) is the ultimate cause and the importance of impurities cannot be precisely evaluated, we favor keeping this name.

The forms of the Thomson crystals. LaChapelle (1968) described four types of Thomson crystals: A, large dendritic or lobate plates; B, thin, clear discs of ice; C, arborescent plates; and D, mushroom crystals. Knight ( 1968 ) performed a version of Helmholtz's experiment (Helmholtz, I 865) in which the ice crystals grew freely into the water, and reproduced types $\mathrm{A}$ and $\mathrm{B}$ on a small scale.

Inspection of the Thomson crystals in the crevasse showed the following correlations between thickness, shape in cross-section, and shape in plan view of the planar crystals (types $\mathrm{A}, \mathrm{B}$, and $\mathrm{C}$ above). The thinnest crystals, up to 2 or $3 \mathrm{~mm}$ thick, had a roughly rectangular 
cross-section and were round or oval in plan. The largest specimen seen was roughly circular (by roughly is meant that it was only slightly oval; there was no trace of scalloping at the edges) and about $\mathrm{I} 5 \mathrm{~cm}$ in diameter. From $2-3 \mathrm{~mm}$ to $\mathrm{I}-2 \mathrm{~cm}$ in thickness, the crystals had a trapezoidal cross-section and a dendritic or lobate plan. These ranged up to $30-40 \mathrm{~cm}$ in longest dimension and the openness of the dendritic structure was highly variable. At one extreme, all dendritic arms and branches were separate and distinct. At the other extreme the plate was nearly solid, with a lobate outline and some conical pits on one side, arranged in a way that suggested that the plate was originally dendritic but that it was almost completely filled in, with only the pits remaining. From $\mathrm{I}-2$ to $2-4 \mathrm{~cm}$ in thickness, the cross-section was notched, as if two of the thinner plates were placed together with their larger faces toward the

THICKNESS

$<2-3 \mathrm{~mm}$

2-3 $\mathrm{mm}$

$1-2 \mathrm{~cm}$
CROSS-SECTION

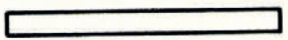

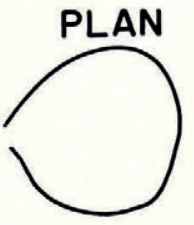

Figs. 11,12

Fig. 2 of

La Chapelle, 1968

$1-2 \mathrm{~cm}$

$2-4 \mathrm{~cm}$

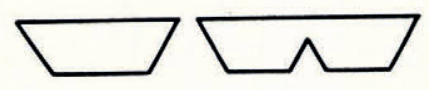

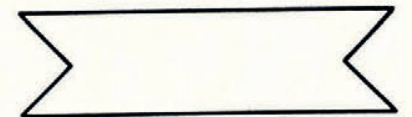

Much Like

Fig. 12

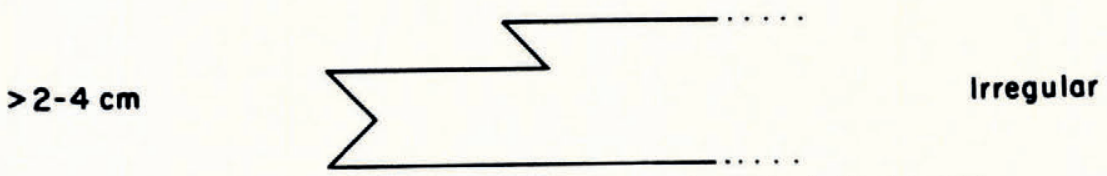

Fig. Io. Shapes of the planar Thomson crystals correlated with their thicknesses.

outside. The plan was still dendritic or lobate, but as a rule much less delicate than that of the thinner crystals. A few even thicker crystals were stepped and had a very irregular outline. Figure ro summarizes these relations, and Figures I I and I 2 show some examples.

There are some exceptions to this classification. A few plates were seen that had rounded projections parallel to the $c$-axis; perhaps a phenomenon similar to the mushroom crystals. Some of the stepped crystals grew from the trapezoidal crystals, not the notched ones as shown in Figure io. The most extreme examples of the arborescent crystals showed virtually no basal plane development: the cross-section of the arms was virtually round. Figure 13 shows this kind of arborescent crystal.

Except for the mushroom crystals and the extreme arborescent crystals, the Thomson crystal forms may be understood qualitatively on the basis of heat-flow arguments, as advanced by Knight (1968). The ice crystals grow by dissipating the heat of fusion into the supercooled, 


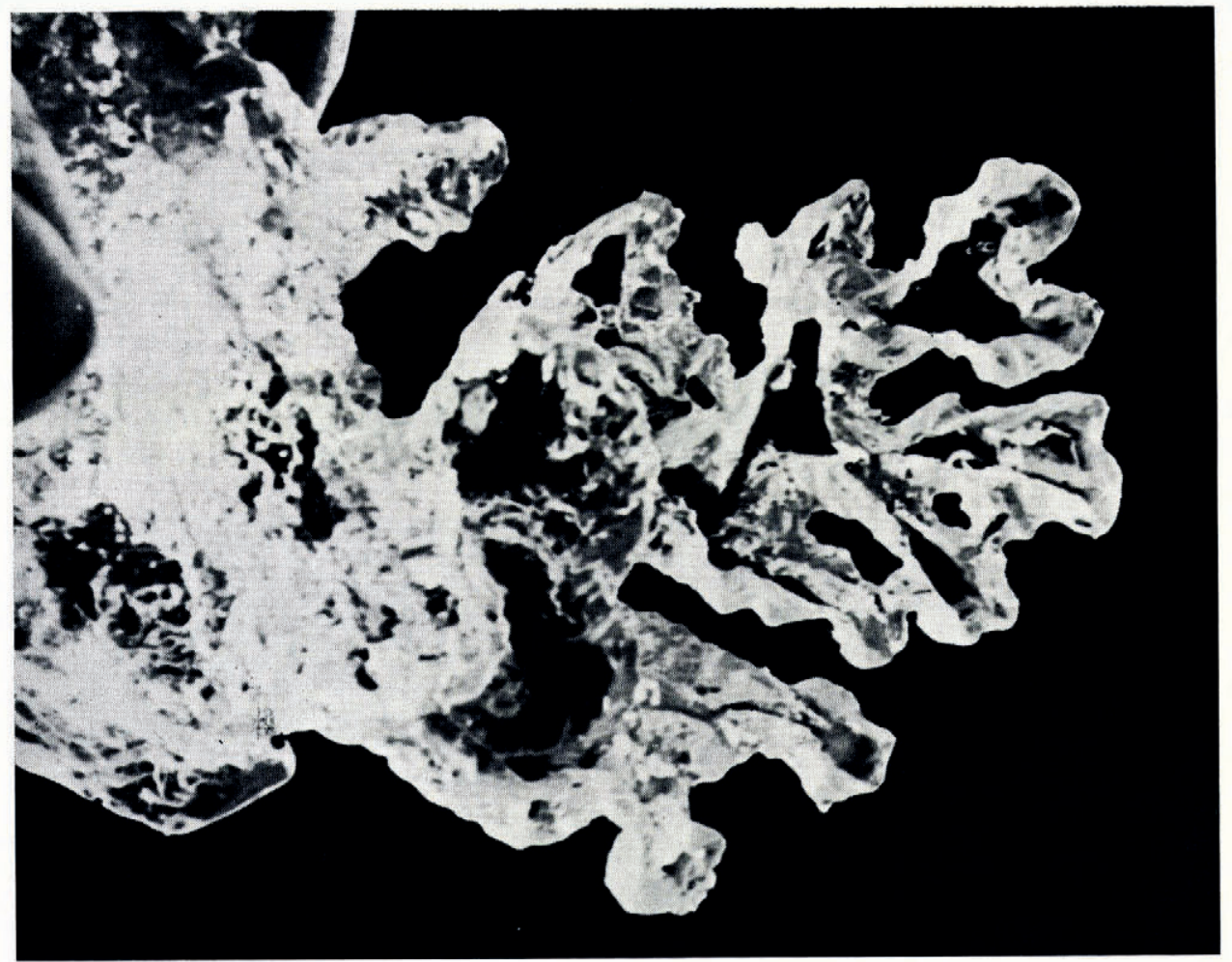

Fig. II. An example of an articulated dendritic form of trapezoidal crystal.

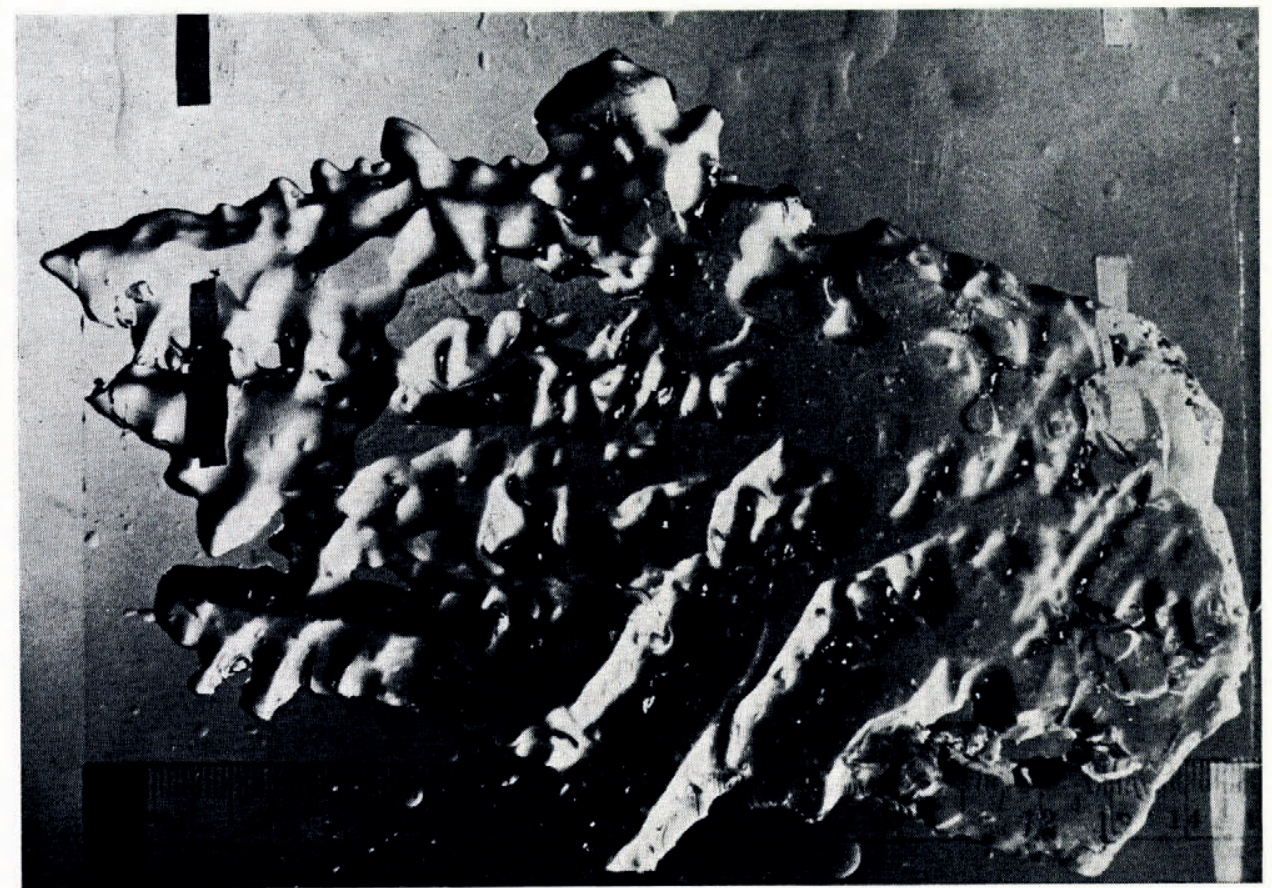

Fig. I2. An example of a closed form of trapezoidal crystal, scale in centimeters. 
surrounding water. The faster they can dissipate this heat, the faster they grow. The planar ice crystals, however, do not grow to any appreciable extent in the direction normal to the plane, for other reasons. Therefore the heat of fusion generated by growth at the edges has two paths: directly into the liquid in contact with the growing edge, and into the ice and thence into the liquid in contact with the basal face or faces. Since the thermal conductivity of ice is about five times that of water, a significant portion of the heat of fusion generated at the edges of the thin discs travels into the ice and then into the liquid. This tends to suppress dendritic growth because heat dissipation into the ice is more effective the flatter the growing interface. The thicker such a planar crystal is, the larger is the proportion of the heat of fusion that much be dissipated directly into the liquid, because the area of basal face available for heat dissipation remains the same. At some thickness (which depends upon the supercooling:

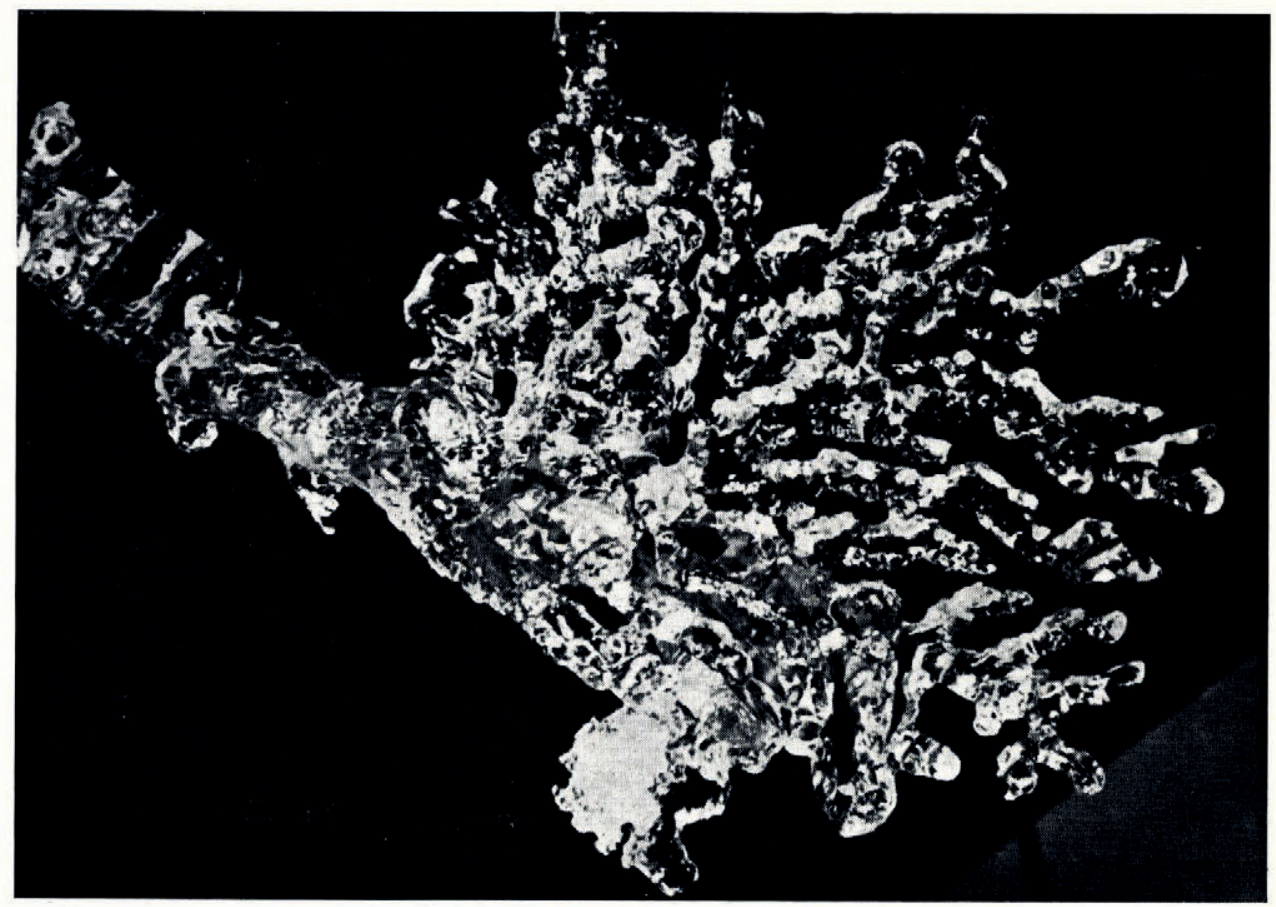

Fig. I3. An example of an arborescent crystal.

in this case about $3 \mathrm{~mm}$ ) the tapered edge with dendritic habit becomes the fastest growth form, and at some greater thickness yet the two sides of the edge are far enough apart that they no longer interfere with each other in dissipating their heat of fusion, and the notched growth form results.

In so far as constitutional supercooling is responsible for the Thomson crystals in the first place, it must also be a factor in the growth of the Thomson crystals themselves. They also must tend to reject impurities, and since they are in places quite densely clustered, the impurity concentrations may be sufficient in places to affect their growth forms.

The mushroom crystals are unique in that they grew fastest parallel to the $c$-axis. They are very rare (found only in I966), which may be because the wall ice only rarely has the crystallographic orientation with $c$-axes perpendicular to the wall surface. It must be assumed that their lateral growth was inhibited by an impurity-rich layer in the water close to the wall surface. Perhaps this is a sufficient reason for this growth form, though it is not very satisfying. 


\section{Discussion}

Because of the generalized Thomson mechanism, dependence of freezing point upon stress and pressure, there must be considerable freezing activity within crevassed, temperate glaciers. The mechanism provides a slow means of sealing crevasses shut at the bottom so that they become water-tight, and then of freezing the water in them into bubble-free ice. The case is very different if the water-filled cavity becomes completely sealed. Then a little freezing will bring about pressure equilibrium and the freezing will stop.

Supercooled water is delivered to free ice surfaces along fine-grained layers in the ice. In the case investigated here, these layers are probably old shear zones that are more or less stagnant. (But if they were completely stagnant it would be difficult to understand why they had not recrystallized into coarser grains. Recrystallization at the melting point, without stress, would be expected to destroy the smaller existing grain sizes within a few months, let alone years.) Though any correlation between deformation and melt-freeze activity is very uncertain in this case, it is none the less interesting in view of current interest in regelation as a deformation mechanism in temperate glaciers.

The Thomson crystal formation is a minor feature, in terms of the amount of ice formed, in comparison with the uniform, inward freezing of the water in the water-filled crevasse.

\section{Acknowledgements}

Dr James Deardorff provided some very helpful discussions on free convection. This work has been supported by National Science Foundation Grants GA-466 and GA-I 516, and in part by the National Center for Atmospheric Research. Field work on the Blue Glacier is made possible by permission of the Superintendant, Olympic National Park.

MS. received 22 May 1969

\section{REFERENCES}

Helmholtz, H. von. 1865. Eis und Gletscher. (In Helmholtz, H. von. Populäre wissenschaftliche Vorträge. Erstes Heft. Braunschweig, F. Vieweg und Sohn, p. 93-134.)

Jackson, K. A., and others. 1967. On the nature of crystal growth from the melt, by K. A. Jackson, D. R. Uhlmann and J. D. Hunt. Fournal of Crystal Growth, Vol. I, No. I, p. I-36.

Knight, C. A. 1962. The polygonization of aged sea ice. Journal of Geology, Vol. 70, No. 2, p. $240-46$.

Knight, C. A. 1968. Growth of ice crystals after a method by Helmholtz. Nature, Vol. 220, No. 5162, p. $62-63$.

LaChapelle, E. R. I968. Stress-generated ice crystals in a nearly isothermal two-phase system. Journal of Glaciology, Vol. 7, No. 50, p. $183-98$.

Steinemann, S. 1958. Experimentelle Untersuchungen zur Plastizität von Eis. Beiträge zur Geologie der Schweiz. Geotechnische Serie. Hydrologie, $\mathrm{Nr}$. 10.

Thomson, J. 1849. Theoretical considerations on the effects of pressure in lowering the freezing point of water. Transactions of the Royal Society of Edinburgh, Vol. 16, Pt. 5, p. 575-8o. 